\title{
Educational level and decreases in leisure time physical activity: predictors from the longitudinal GLOBE study
}

\author{
M Droomers, C T M Schrijvers, J P Mackenbach
}

\begin{abstract}
Study objective-This study describes educational differences in decreases in leisure time physical activity among an adult, physically active population and additionally attempts to identify predictors of these differences from information on health status and individual and environmental factors.
\end{abstract}

Design-Prospective population based study. Baseline measurement were carried out in 1991 and follow up in 1997. Setting-South eastern part of the Netherlands.

Participants-The study included 3793 subjects who were physically active in 1991 and who participated in the follow up. Methods-Potential predictors of decreasing physical activity were measured in 1991. Logistic regression analyses were carried out for two age groups ( $<45$ years; $\geqslant 45$ years) separately.

Main results-Lower educated respondents experienced statistically significant higher odds to decrease physical activity during follow up, compared with respondents with higher vocational schooling or a university degree. Perceived control was the main predictor of educational differences in decreasing physical activity in both age groups. In the older group, material problems and a poor perceived health experienced by lower educated people additionally predicted educational differences in decreases in physical activity during leisure time.

Conclusions-These findings have important implications for health promotion practice and policy to prevent socioeconomic differences in physical inactivity and health. There is a need for evidencebased interventions that improve perceived control and reduce material problems in lower educated groups. (F Epidemiol Community Health 2001;55:562-568)

Department of Public Health, Erasmus University Rotterdam, PO Box 1738, 3000 DR Rotterdam, the Netherlands

Correspondence to: M Droomers

(droomers@mgz.fgg.eur.nl)

Accepted for publication 23 March 2001 decreasing physical activity could accordingly contribute to socioeconomic health differences.

General health promotion activities to reduce unhealthy behaviour have been relatively unsuccessful in lower socioeconomic groups so far. ${ }^{14-16}$ Prevention of unhealthy (changes in) behaviour in these groups therefore might prove to be more effective. This study is the first to combine a description of educational differences in decreasing leisure time physical activity among an adult, initially active population with the identification of specific characteristics of lower educated groups that predict their higher odds to decrease physical activity. Knowledge of the predictors of socioeconomic differences in decreases in physical activity might be a valuable input for more effective health promotion policies and activities that tackle socioeconomic differences in physical activity.

Our study included information on three groups of potential predictors of decreasing physical activity - that is, health status, individual factors, and environmental factors. Decreases in physical activity are often preceded by poor subjective health, ${ }^{5}$ as well as more objective health indicators such as low functional status, ${ }^{6}{ }^{17}$ diabetes mellitus, ${ }^{18}$ high cholesterol, ${ }^{18}$ and increases in, or a high body mass index. ${ }^{6} 8918$

Furthermore, decreasing physical activity is often embedded in a more general unhealthy lifestyle. People who experience subsequent decreases in physical activity are reported to smoke $^{5818}$ and consume alcohol ${ }^{8}$ more often than people with stable activity patterns. They also have specific personality characteristics more often, such as high personal uncertainty, ${ }^{5}$ or low perceived control over life. ${ }^{7}$ Other individual circumstances, such as family or work responsibilities may influence physical activity ${ }^{4920}$ because of competing time claims.

The environment exerts considerable influence on individual behaviour. ${ }^{822} 23$ Environmental factors, like life events or material problems potentially induce stress that could adversely influence physical activity. ${ }^{6}$ Furthermore, environmental circumstances, like lack of economic resources or facilities can affect opportunities for physical activity. ${ }^{9} 1920$

We know that the predictors described above are distributed unequally over socioeconomic groups. ${ }^{323}$ For example, poor health or material disadvantages occur more often in lower socioeconomic groups and may therefore give rise to 
socioeconomic differences in decreasing physical activity.

\section{Methods}

POPULATION

Data were obtained from the longitudinal study on socioeconomic health differences in the Netherlands (GLOBE study). ${ }^{24}$ In 1991, a random sample of approximately 27000 persons, drawn from registers of the general noninstitutionalised population aged $15-74$ years, received a postal questionnaire (response $70.1 \%$ ). Two subsamples from respondents to the postal questionnaire were additionally interviewed (response $79.4 \%$ and $72.3 \%$ ). People who reported specific chronic diseases were overrepresented in one subsample. Nonrespondents only differed from respondents in the subsample that overrepresented chronically ill persons, regarding age and marital status. ${ }^{24} 25$ In 1997, of the 5667 subjects participating in the interviews in $1991,328(5.8 \%)$ had deceased, $39(0.7 \%)$ moved abroad, 316 $(5.6 \%)$ refused to further participate in the longitudinal study before follow up measurement, while $37(0.7 \%)$ could not be traced. This left 4947 persons (87.3\%) eligible for enrolment in the follow up measurements in 1997, of whom 4246 persons returned the postal questionnaire (response $85.8 \%$ ).

\section{MEASURES}

Physical activity during leisure time was assessed using three questions in the postal questionnaires. ${ }^{26}$ Respondents filled in (1) the average minutes spent walking or cycling to work or shops every day. They also stated (2) how much time they spent on average on leisure time gardening, cycling, walking, and, separately (3) on active sports, per week (appendix). Minutes spent on daily walking and cycling were multiplied by 6 to calculate time spent weekly and successively added to the time spent on leisure time gardening, cycling, and walking per week. This categorical information on total time spent on gardening, cycling, and walking was combined with time spent on sports into total leisure time physical activity, giving double weight to time spent on sports. Physical activity was divided into four categories; completely sedentary, lightly active, moderately active, and highly active (appendix). Decreased physical activity was defined as being categorised one or more categories lower in 1997 than in 1991. Only respondents who were active in 1991 and at risk of decreasing their activity were included in the analyses $(n=3978)$. Information on physical activity in 1997 was missing for 122 respondents (3.1\%).

Highest attained educational level was measured in the postal questionnaire in 1991 and divided into four categories - that is, higher vocational schooling and university ( 1 =high), intermediate vocational schooling or intermediate/higher secondary schooling (2), lower secondary or vocational schooling (3), and primary school only ( $4=$ low). Sixty three respondents $(1.6 \%)$ did not report their educational level. Educational level has the advantage that it is available for both men and women, whether they are in paid employment or not, it does not change during adult life, it has a high reliability and validity ${ }^{27}$ and it is simple to measure and use.

Health status was indicated by perceived general health, the presence of at least one self reported severe chronic condition, the Nottingham Health Profile, and obesity. All questions were included in the postal questionnaire of 1991. Perceived general health was assessed by asking "How do you rate your health in general?" 28 Severe chronic conditions comprised heart disease, pulmonary disease, stroke, peptic ulcer, kidney disorders, diabetes, rheumatism or arthritis, illness of the nervous system, and cancer, which were part of a 24 item checklist. ${ }^{28}$ The Nottingham Health Profile reflects health problems in six areas: emotional reaction, energy, sleep, pain, physical mobility, and social isolation. ${ }^{29}$ Obesity was defined as a body mass index (self reported weight $(\mathrm{kg}) / \mathrm{height}^{2}(\mathrm{~m})$ ) of at least 30 .

Individual factors included alcohol consumption, smoking, family and work responsibilities, neuroticism and perceived control. All were included in the postal questionnaire of 1991, except neuroticism and perceived control, which were questioned during the interview. Alcohol consumption was questioned using a quantity-frequency method. ${ }^{30}$ Three smoking categories were distinguished - that is, current smokers, ex-smokers and those who have never smoked. Work responsibilities were indicated by being employed, unemployed, or housekeeper (engaged in household duties). The number of children living at home with the respondent indicated family responsibilities. Locus of control indicated perceived control, measured with a questionnaire based on Rotter's locus of control scale. ${ }^{31}$ A Dutch translation of the Eysenck Personality Questionnaire measured neuroticism. ${ }^{32}$ The scores of locus of control and neuroticism were classified into five equally sized categories (quintiles).

Environmental factors were life events, longlasting difficulties, equivalent income, the occurrence of financial problems, situational difficulties, and housing and neighbourhood circumstances. All were questioned during the interview in 1991, except for life events and financial problems, which were included in the postal questionnaire. Nine negative life events in the preceding year included serious illness or death of important persons, substantial decrease in income, or being a victim of robbery or theft. ${ }^{33}$ Longlasting difficulties during the preceding year were measured with an adapted version of the Dutch Long Lasting Difficulties List. ${ }^{34}$ Difficulties with health problems of significant others were added up. The score on items of relational and situational difficulties ranged from 0 (no problem or not applicable) to 3 (serious problem) and were added up to arrive at a total score. Equivalent income was defined as total net household income divided by the number of persons depending on that income, giving more weight to adults than to children and classified into five equally sized groups (quintiles). Financial problems were indicated by not being able to pay the rent, 
Table 1 Educational differences in decreasing physical activity

\begin{tabular}{|c|c|c|c|c|c|c|c|c|}
\hline \multirow[b]{2}{*}{ Educational level } & \multicolumn{4}{|c|}{ Younger than 45 years } & \multicolumn{4}{|c|}{45 years and older } \\
\hline & Number* & $\%$ & OR & $95 \% C I$ & Number* & $\%$ & $O R$ & $95 \% C I$ \\
\hline High (1) & 348 & 18.8 & 1.00 & & 411 & 17.0 & 1.00 & \\
\hline 2 & 439 & 30.1 & 1.94 & $1.37,2.74$ & 457 & 16.5 & 1.01 & $0.69,1.47$ \\
\hline 3 & 423 & 31.0 & 2.57 & $1.81,3.65$ & 1038 & 19.6 & 1.36 & $0.98,1.89$ \\
\hline Low (4) & 87 & 41.3 & 4.98 & $2.91,8.53$ & 590 & 23.6 & 2.41 & $1.68,3.46$ \\
\hline Total & 1297 & 28.0 & & & 2496 & 20.0 & & \\
\hline
\end{tabular}

^Number of respondents physically active in 1991. \%, Weighted prevalence of decreased physical activity between 1991 and 1997. OR, odds ratio of decreasing physical activity, adjusted for gender, age, and physical activity in $1991.95 \%$ CI, $95 \%$ confidence intervals of $\mathrm{OR}$.

electricity or food during the preceding year. Housing conditions were examined by asking whether draught, cold, or damp were present. ${ }^{33}$ Four items on adverse neighbourhood conditions included stench, noise from neighbours, noise from traffic, and criminality. ${ }^{33}$

Table 2 continued on next page

\begin{tabular}{|c|c|c|c|c|c|c|}
\hline & \multicolumn{3}{|c|}{ Younger than 45 years } & \multicolumn{3}{|c|}{45 years and older } \\
\hline & $O R$ & $95 \% C I$ & Test & $O R$ & $95 \% C I$ & Test \\
\hline \multicolumn{7}{|c|}{ A Association between health status and decreasing physical activity } \\
\hline \multicolumn{6}{|c|}{ Severe chronic conditions } & $\star \star$ \\
\hline none & 1.00 & & & 1.00 & & \\
\hline at least one problem & 1.22 & $0.85,1.75$ & & 1.38 & $1.10,1.73$ & \\
\hline \multicolumn{6}{|l|}{ NHP emotions } & $\star$ \\
\hline no problems & 1.00 & & & 1.00 & & \\
\hline at least one problem & 1.04 & $0.76,1.44$ & & 1.34 & $1.04,1.72$ & \\
\hline \multicolumn{6}{|l|}{ NHP energy } & $\star \star$ \\
\hline no problems & 1.00 & & & 1.00 & & \\
\hline at least one problem & 1.18 & $0.78,1.79$ & & 1.51 & $1.13,2.02$ & \\
\hline \multicolumn{6}{|l|}{ NHP isolation } & $\star \star$ \\
\hline no problems & 1.00 & & & 1.00 & & \\
\hline at least one problem & 1.58 & $0.98,2.54$ & & 1.71 & $1.21,2.42$ & \\
\hline \multicolumn{6}{|l|}{ NHP mobility } & $\star \star \star \star$ \\
\hline no problems & 1.00 & & & 1.00 & & \\
\hline at least one problem & 1.44 & $0.98,2.13$ & & 1.69 & $1.34,2.14$ & \\
\hline \multicolumn{6}{|l|}{ NHP pain } & $\star \star \star$ \\
\hline no problem & 1.00 & & & 1.00 & & \\
\hline at least one problem & 1.09 & $0.72,1.64$ & & 1.67 & $1.32,2.12$ & \\
\hline \multicolumn{7}{|l|}{ NHP sleep } \\
\hline no problem & 1.00 & & & 1.00 & & \\
\hline at least one problem & 1.21 & $0.86,1.70$ & & 1.46 & $0.94,2.28$ & \\
\hline \multicolumn{6}{|l|}{ Self perceived health } & $\star \star \star$ \\
\hline (very) good & 1.00 & & & 1.00 & & \\
\hline less than good & 1.31 & $0.92,1.88$ & & 1.93 & $1.52,2.44$ & \\
\hline \multicolumn{7}{|l|}{ Obesity } \\
\hline $\mathrm{BMI}<30$ & 1.00 & & & 1.00 & & \\
\hline $\mathrm{BMI} \geqslant 30$ & 1.22 & $0.63,2.36$ & & 1.46 & $0.94,2.28$ & \\
\hline \multicolumn{7}{|c|}{ B Association between individual factors and decreasing physical activity } \\
\hline \multicolumn{6}{|c|}{ Alcohol consumption } & $\star$ \\
\hline abstainer & 1.00 & & & 1.00 & & \\
\hline light drinking & 0.79 & $0.56,1.13$ & & 0.70 & $0.53,0.92$ & \\
\hline moderate drinking & 0.49 & $0.31,0.78$ & & 0.83 & $0.60,1.14$ & \\
\hline (very) excessive drinking & 1.34 & $0.76,2.34$ & & 1.20 & $0.78,1.07$ & \\
\hline \multicolumn{6}{|l|}{ Smoking } & $\star \star \star$ \\
\hline never smoked & 1.00 & & & 1.00 & & \\
\hline ex smoker & 1.00 & $0.71,1.42$ & & 0.99 & $0.75,1.31$ & \\
\hline smoker & 1.26 & $0.95,1.68$ & & 1.56 & $1.17,2.09$ & \\
\hline Work responsibilities & & & & & & \\
\hline not employed & 1.00 & & & 1.00 & & \\
\hline housekeeper & 0.83 & $0.50,1.39$ & & 1.03 & $0.72,1.48$ & \\
\hline employed & 0.89 & $0.60,1.32$ & & 1.03 & $0.74,1.42$ & \\
\hline Family responsibilities & & & $\star \star$ & & & \\
\hline no children & 1.00 & & & 1.00 & & \\
\hline 0 living at home & 1.19 & $0.50,2.84$ & & 0.71 & $0.50,1.00$ & \\
\hline 1 living at home & 1.87 & $1.26,2.83$ & & 0.82 & $0.56,1.21$ & \\
\hline 2 living at home & 1.10 & $0.74,1.63$ & & 0.79 & $0.52,1.20$ & \\
\hline 3 or more living at home & 0.66 & $0.38,1.17$ & & 0.58 & $0.29,1.13$ & \\
\hline Locus of control & & & $\star \star$ & & & $\star \star \star$ \\
\hline internal & 1.00 & & & 1.00 & & \\
\hline 2 & 1.43 & $1.04,1.96$ & & 1.58 & $1.06,2.37$ & \\
\hline 3 & 1.34 & $0.92,1.95$ & & 1.79 & $1.18,2.72$ & \\
\hline 4 & 1.98 & $1.35,2.92$ & & 2.17 & $1.47,3.20$ & \\
\hline external & 1.79 & $1.10,2.90$ & & 2.26 & $1.53,3.33$ & \\
\hline Neuroticism & & & $\star$ & & & \\
\hline hardly & 1.00 & & & 1.00 & & \\
\hline 2 & 1.23 & $0.81,1.87$ & & 0.81 & $0.57,1.14$ & \\
\hline 3 & 1.49 & $0.98,2.28$ & & 1.19 & $0.84,1.67$ & \\
\hline 4 & 1.28 & $0.86,1.92$ & & 0.80 & $0.57,1.13$ & \\
\hline highly & 1.87 & $1.28,2.73$ & & 1.13 & $0.83,1.55$ & \\
\hline
\end{tabular}

ANALYSES

After excluding cases with missing values 3793 people were included in the analyses. Logistic regression models with decreasing physical activity as dependent variable and adjusted for gender, age, and physical activity at baseline, were fitted. Furthermore, we adjusted for the overrepresentation of chronically ill. We therefore proportionately weighted the information of the different subgroups (chronically ill and healthy people) to resemble the composition of the population that responded to the postal questionnaire in 1991.

Educational differences in decreasing physical activity did not differ by gender, but were related to age (education ${ }^{\star}$ age $\mathrm{p}<0.001$ ). Explanatory analyses have therefore been carried out separately for the group younger than 45 years $(n=1297)$ and the group of 45 years and older $(\mathrm{n}=2469)$.

To test if variables predicted educational differences in decreasing leisure time physical activity, the following procedure was followed. Firstly, each variable was added successively to a logistic model with confounders only. Variables were considered predictors of decreasing physical activity when they showed a statistically significant likelihood ratio $\chi^{2}$ test $(\mathrm{p}<0.05)$, and a clear relation with decreasing physical activity (statistically significantly increased odds ratio). Secondly, the relation between predictors of decreasing physical activity and educational level was described. Thirdly, each predictor of decreasing physical activity, which was inversely related to education, was added to a logistic model containing education and confounders, in order to quantify the prediction of educational differences in decreasing physical activity. This prediction was expressed by the reduction in odds ratios of the different educational groups (should be more than $5 \%$ in at least one of the educational groups and no substantial increase of other odds ratios) ànd the part of the reduction in deviance attributable to education, which was accounted for by inclusion of the predictor in the model (see footnote tables 3 and 4).

\section{Results}

Almost a quarter of the initially active respondents decreased their physical activity level between 1991 and 1997 (table 1). Almost one fifth of the persons who reduced their physical activity became sedentary. Most respondents $(80 \%)$ only decreased one category.

Educational differences in decreasing physical activity were much larger among the 
PREDICTORS OF DECREASING PHYSICAL ACTIVITY IN THE YOUNGER GROUP

Table 2 shows the relation between potential predictors and decreasing physical activity. Health status was not related to declines in physical activity in the younger group. Several individual factors, however, resulted in decreasing physical activity during follow up, like having one child and reporting lower perceived control or high scores on the neuroticism scale. Low equivalent income was the only environmental factor related to decreasing physical activity. All these risk factors occurred more frequently in lower educated groups - that is, they more often reported having one child living at home, low perceived control, and low equivalent income (not tabulated). Neuroticism was ambiguously related to educational level, showing a high prevalence of the highest neuroticism scores in the lower educated groups, but the second highest neuroticism scores occurring more often in the highest educated groups (not tabulated).

PREDICTORS OF DECREASING PHYSICAL ACTIVITY IN THE OLDER GROUP

Table 2 shows that in the older group all self reported health problems, except the Nottingham sleep profile and obesity, predicted decreasing physical activity during follow up. People who smoked or reported lower perceived control experienced decreases in physical activity during follow up more frequently. Also people with lower equivalent incomes, financial problems, or detrimental housing conditions experienced declines in physical activity more often. All risk factors for decreasing activity among this older group occurred more often in lower educated groups (not tabulated). This was particularly true for perceived general health. der, age, and physical activity in $1991.95 \%$ CI, $95 \%$ confidence intervals of OR. Test, likelihood ratio $\chi^{2}$ test.

younger group (table 1). Persons with primary school only in the younger group experienced an almost five times higher chance to decline in physical activity compared with the reference group. Among persons older than 44 years, the lowest educated group was almost 2.5 times more likely to decrease physical activity during follow up than persons who had finished higher vocational schooling or university.

PREDICTION OF EDUCATIONAL DIFFERENCES IN DECREASING PHYSICAL ACTIVITY

Variables that predicted decreases in physical activity (table 2) were all related to educational level and therefore selected into analyses of the contribution of each variable to the prediction of educational differences in decreasing physical activity.

Educational differences in decreasing physical activity in the younger group were predicted

Table 3 Explanation of educational differences in decreasing physical activity in the group younger than 45 years

\begin{tabular}{|c|c|c|c|c|c|c|c|}
\hline \multirow[b]{2}{*}{ Educational level } & \multirow{2}{*}{$\begin{array}{l}\text { Model } A \\
\text { OR }\end{array}$} & \multicolumn{2}{|c|}{ Model $A+$ locus of control } & \multicolumn{2}{|c|}{$\begin{array}{l}\text { Model } A+\text { family } \\
\text { responsibility }\end{array}$} & \multicolumn{2}{|c|}{ Model $A+$ both } \\
\hline & & $O R$ & $\%$ & $O R$ & $\%$ & $O R$ & $\%$ \\
\hline High (1) & 1.00 & 1.00 & & 1.00 & & 1.00 & \\
\hline 2 & $1.94^{\star}$ & $1.82^{\star}$ & 13 & $1.89^{\star}$ & 12 & $1.76^{\star}$ & 19 \\
\hline 3 & $2.57^{\star}$ & $2.41^{\star}$ & 10 & $2.46^{\star}$ & 7 & $2.28^{\star}$ & 18 \\
\hline Low (4) & $4.98^{\star}$ & $4.44^{\star}$ & 14 & $4.49^{\star}$ & 5 & $3.94^{\star}$ & 26 \\
\hline $\mathrm{RD}$ education $\dagger$ & 45.576 & 40.910 & & 38.658 & & 28.320 & \\
\hline $\mathrm{p}$ value $\mathrm{RD}$ education & 0.0000 & 0.0000 & & 0.0000 & & 0.0000 & \\
\hline$\Delta \mathrm{RD}$ education $\ddagger$ & & 4.666 & & 6.918 & & 17.256 & \\
\hline$\% \Delta \mathrm{RD} \mathbb{S}$ & & 10.2 & & 15.2 & & 37.9 & \\
\hline
\end{tabular}

Model A includes confounders and educational level. ${ }^{\star} 95 \%$ confidence intervals do not include 1 . OR, odds ratio, adjusted for gender, age, and physical activity in $1991 . \%, \%$ reduction in odds ratio $=(\mathrm{OR}$ model A - OR model A + predictor $) /($ OR model A 1). + Reduction in deviance due to inclusion of education in the model. $\ddagger \Delta \mathrm{RD}=$ (reduction in deviance due to education of model A) - (reduction in deviance due to education of model A + predictor). \$Percentage explained of reduction in deviance due to inclusion of education in model $\mathrm{A}=(\Delta \mathrm{RD} / \mathrm{RD}$ education of model $\mathrm{A}) \times 100 \%$. 
Table 4 Explanation of educational differences in decreasing physical activity in the group of 45 years and older

\begin{tabular}{|c|c|c|c|c|c|c|c|c|c|c|c|}
\hline \multirow[b]{2}{*}{ Educational level } & \multirow{2}{*}{$\begin{array}{l}\text { Model } A \\
\text { OR }\end{array}$} & \multicolumn{2}{|c|}{$\begin{array}{l}\text { Model } A+\text { perceived } \\
\text { general health }\end{array}$} & \multicolumn{2}{|c|}{$\begin{array}{l}\text { Model } A+\text { locus of } \\
\text { control }\end{array}$} & \multicolumn{2}{|c|}{$\begin{array}{l}\text { Model A + housing } \\
\text { conditions }\end{array}$} & \multicolumn{2}{|c|}{$\begin{array}{l}\text { Model } A+\text { financial } \\
\text { problems }\end{array}$} & \multicolumn{2}{|c|}{ Model $A+$ all } \\
\hline & & $O R$ & $\%$ & $O R$ & $\%$ & $O R$ & $\%$ & $O R$ & $\%$ & $O R$ & $\%$ \\
\hline High (1) & 1.00 & 1.00 & & 1.00 & & 1.00 & & 1.00 & & 1.00 & \\
\hline 2 & 1.01 & 0.94 & & 0.90 & & 0.98 & & 0.96 & & 0.85 & \\
\hline 3 & 1.36 & 1.23 & 36 & 1.19 & 47 & 1.30 & 17 & 1.30 & 17 & 1.09 & 75 \\
\hline Low (4) & $2.41^{\star}$ & $2.01^{\star}$ & 28 & $1.99^{\star}$ & 30 & $2.21^{\star}$ & 14 & $2.20^{\star}$ & 15 & 1.68 & 52 \\
\hline $\mathrm{RD}$ education $\dagger$ & 33.037 & 21.459 & & 22.742 & & 27.502 & & 26.781 & & 14.001 & \\
\hline $\begin{array}{l}\mathrm{p} \text { value } \mathrm{RD} \\
\text { education }\end{array}$ & 0.0000 & 0.0001 & & 0.0000 & & 0.0000 & & 0.0000 & & 0.0029 & \\
\hline$\Delta \mathrm{RD}$ education $\ddagger$ & & 11.578 & & 10.295 & & 5.535 & & 6.256 & & 19.036 & \\
\hline$\% \Delta \mathrm{RD} \$ & & 35.0 & & 31.2 & & 16.8 & & 18.9 & & 57.6 & \\
\hline
\end{tabular}

Model A includes confounders and educational level. ${ }^{\star} 95 \%$ confidence intervals do not include 1. OR, odds ratio, adjusted for gender, age, and physical activity in $1991 . \%, \%$ reduction in odds ratio $=($ OR model $\mathrm{A}-$ OR model $\mathrm{A}+$ predictor $) /($ OR model $\mathrm{A}-1)$. $\dagger$ Reduction in deviance due to inclusion of education in the model. $\ddagger \Delta \mathrm{RD}=$ (reduction in deviance due to education of model $\mathrm{A}$ ) - (reduction in deviance due to education of model $\mathrm{A}+$ predictor). $\$$ Percentage explained of reduction in deviance due to inclusion of education in model $\mathrm{A}=(\Delta \mathrm{RD} / \mathrm{RD}$ education of model $\mathrm{A}) \times 100 \%$.

partly by perceived control and family responsibilities (table 3). Both predictors together decreased the odds ratios with about $20 \%$, and explained more than one third of the educational variation in decreasing physical activity (\%RD). Neuroticism and equivalent income did not predict the educational differences in decreasing activity. The remaining educational differences were however still statistically significant. The lowest educated group was still almost four times more likely to experience decreases in activity compared with the highest educational group.

Educational differences in decreasing physical activity in the older group were predicted by the low perceived control in lower educated groups as well (table 4). Furthermore, less than good perceived health, financial problems and detrimental housing conditions contributed to educational differences in decreasing physical activity (table 4). Equivalent income and the Nottingham Health Profile did not predict educational differences. The four predictors together accounted for more than half of the increased odds of decreasing physical activity in the lower educated groups, while the educational variation was reduced with almost $60 \%(\% \mathrm{RD})$ and educational differences were no longer statistically significant.

\section{Discussion}

We report results from a longitudinal study, showing that adverse changes in physical activity during leisure time were more frequent in lower educated groups. Low perceived control in the lower educated groups was the most important predictor of educational differences in decreasing physical activity. Educational differences in the younger group were further predicted by family responsibilities. In the older group, poor perceived health and problems with finances and housing predicted more decreasing leisure time activity in lower educated groups.

Limitations of the study need to be considered in the interpretation of the results. Firstly, people lost to follow up were less active in 1991. Less active persons do decrease their physical activity less often $(p<0.0001)$ and are more prevalent in lower educated groups. This might have resulted in an overestimation of educational differences in decreasing activity. Furthermore, loss to follow up was higher in lower educated groups and those lost to follow up showed higher prevalence of predictors of decreasing physical activity, like lower perceived control and poor perceived health. Those lost to follow up therefore can be expected to relatively more often have decreased physical activity. This suggests that the presented educational differences in decreasing physical activity might have been underestimated because of selective loss to follow up.

Secondly, physical activity was self reported. We, however, assume reporting bias to have the same impact in both years, not influencing analyses of changes in physical activity.

Thirdly, the study was not specifically designed to predict long term physical activity change. Therefore, we could not include well known predictors of behavioural change, such as self efficacy, ${ }^{21}$ cognitive and motivational factors, ${ }^{22} 35$ and stages of change assessments. ${ }^{36}$

Fourthly, the six and a half year span between data collection periods is rather long. It is impossible to know when the observed changes occurred and what other temporary changes in physical activity and predictors may have occurred in the mean time.

Perceived control was the main predictor of educational differences in decreasing physical activity in both age groups. Many authors have emphasised self control to be a powerful predictor of behavioural change. ${ }^{21}{ }^{37-39}$ People with low perceived control lack confidence about the relation between behaviour and outcomes, and have lower perceived abilities to produce desired outcomes or prevent undesired outcomes themselves, leading to passivity. ${ }^{38} 39$ Furthermore, it has been acknowledged that low perceived control is more common among lower educated persons. ${ }^{39-41}$ We think that health promotion could benefit from finding ways to stimulate control beliefs in lower social classes. In any case, interventions targeting physical activity should anticipate the low control beliefs of lower socioeconomic groups to increase their effectiveness.

Family responsibilities - that is, having one child living at home - adversely changed physical activity in the younger group and occurred more frequently in lower educated respondents. On the other hand, having two or more children at home was related to a stable activity pattern and was more prevalent among higher educated persons. Respondents with one child 
KEY POINTS

- Lower educated people are at higher risk to decrease their physical activity level, compared with higher educated persons.

- Low perceived control over life is an important characteristic of lower educated groups that predict their higher risk of decreasing physical activity.

- Material problems and poor health experienced by older lower educated people are responsible for educational differences in decreasing physical activity.

may be more likely to have another child during follow up and increase their time limitations for activity, compared with respondents having more children already at baseline. On the other hand, the number of children might also be a marker of socioeconomic status - that is, the more children, the higher the socioeconomic status, the lower the chance to decrease physical activity.

Perceived general health was as important a predictor of decreasing physical activity as low perceived control in the older group. Physical unfitness or disease is often proposed an important predictor of unfavourable changes in physical activity. ${ }^{9} 101719$ Other, more "objective" health measures, however, failed to contribute to the explanation of educational differences in decreasing activity. Poor perceived physical condition of lower educated people above their mid-40s could be overcome by emphasising convenient, less strenuous activities in health information.

Material factors, in particular poor housing conditions and financial problems (but not income) predicted educational differences in decreasing physical activity in the older group. These findings suggest that it is not the low status aspect of a disadvantaged material position that is important, but the problems (barriers) people may experience as a consequence of this position. A wide range of policies could potentially influence physical activity, such as financial redistribution systems, financial management courses, collective renovation of houses in low socioeconomic neighbourhoods, or decisions to increase the number of accessible and inexpensive facilities for physical activity.

The predictors of educational differences in decreasing physical activity identified in this paper imply several possibilities for health promotion programmes and policies to reduce socioeconomic differences in physical inactivity. Low perceived control, poor health and material hardship need to be dealt with in health education, health promotion programmes and policies that may affect health behaviour.

The GLOBE study is being carried out by the Department of Public Health of Erasmus University Rotterdam, in collaboration with the municipal health services of the city of Eindhoven tion with the municipal health services of the city of Eindhoven
and the region of southeast Brabant. The authors would like to and the region of southeast Brabant. The authors would like to
thank Gerard Borsboom for his support in statistical matters thank Ilse Oonk and Roel Faber for effectuating and providing the and Ilse Oon
database.
Funding: The Netherlands Health Research and Development Council (ZON) and the Ministry of Public Health, Welfare and Sports financially support the GLOBE study.

Conflicts of interest: none. Appendix

\section{Appendix}

Measurement and categories of physical activity

How much time do you spend on average walking or cycling to work or shops per day?

... minutes.

How much time do you spend on average gardening,

leisure cycling or walking per week?

- no time

- less than 1 hour

- 1 to 2 hours

- more than 2 hours

How much time do you spend on average on active sports per week?

- no time

- less than 1 hour

- 1 to 2 hours

- more than 2 hours

Physical activity categories

\begin{tabular}{|c|c|c|c|c|}
\hline & \multicolumn{4}{|c|}{ Sports } \\
\hline & none & $<1$ hour & 1-2 hours & $>2$ hours \\
\hline \multicolumn{5}{|c|}{ Leisure activity } \\
\hline none & no & light & moderate & high \\
\hline$<1$ hour & light & light & moderate & high \\
\hline 1-2 hours & light & moderate & moderate & high \\
\hline$>2$ hours & light & moderate & high & high \\
\hline
\end{tabular}

1 Blaxter M. Health and lifestyles. London: Tavistock/ Routledge, 1990.

2 Droomers M, Schrijvers CTM, van de Mheen H, et al. Educational differences in leisure-time physical activity: a descriptive and explanatory study. Soc Sci Med 1998;47: 1665-76.

3 Townsend P, Davidson N. The Black report. In: Townsend $\mathrm{P}$, Davidson N, Whitehead M, eds. Inequalities in health. London: Penguin Books, 1988:31-213.

4 Anderssen N, Jacobs DR, Sidney S, et al. Change and secular trends in physical activity patterns in young adults: a seven-year longitudinal follow-up in the Coronary Artery Risk Development in Young Adults Study (CARDIA). Am f Epidemiol 1996;143:351-62.

5 Kaplan GA, Lazarus NB, Cohen RD, et al. Psychosocial factors in the natural history of physical activity. Am $\mathcal{F}$ Prev Med 1991;7:12-17.

6 King AC, Kierman M, Oman RF, et al. Can we identify who will adhere to long-term physical activity? Signal detection methodology as a potential aid to clinical decision making. methodology as a potential aid
Health Psychol 1997;16:380-9.

7 Sallis JF, Haskell WL, Fortmann SP, et al. Predictors of adoption and maintenance of physical activity in a community sample. Prev Med 1986;15:331-41.

8 Sallis JF, Hovell MF, Hofstetter CR. Predictors of adoption and maintenance of vigorous physical activity in men and women. Prev Med 1992;21:237-51.

9 Schmitz K, French SA, Jeffery RW. Correlates of changes in leisure time physical activity over 2 years: the healthy worker project. Prev Med 1997;26:570-9.

10 Blair SN, Kohl HW, Barlow CE, et al. Changes in physical fitness and all-cause mortality. $\mathscr{F} A M A$ 1995;273:1093-8.

11 Kaplan GA, Strawbridge WJ, Cohen RD, et al. Natural history of leisure-time physical activity and its correlates: associations with mortality from all causes and cardiovascular disease over 28 years. Am f Epidemiol 1996;144:793-7.

12 Lissner L, Bengtsson C, Björkelund C, et al. Physical activLissner L, Bengtsson C, Bjorkelund C, et al. Physical activ-
ity levels and changes in relation to longevity. A prospective study of Swedish women. Am ₹ Epidemiol 1996;143:54-62.

13 Paffenbarger Jr RS, Hyde RT, Wing AL, et al. The association of changes in physical-activity level and other lifestyle characteristics with mortality among men. N Engl f Med 1993;328:538-45.

14 Freimuth VS, Mettger W. Is there a hard-to-reach audience? Public Health Rep 1990;105:232-8.

15 Illsley R. Comparative review of sources, methodology and knowledge. Soc Sci Med 1990;31:229-36.

16 Rogers EM. Diffusion of innovations. New York: The Free Press, 1995

17 Bijnen FCH, Feskens EJM, Caspersen CJ, et al. Age, period and cohort effects on physical activity among elderly men during 10 years of follow-up: the Zutphen elderly study. $\mathcal{F}$ Gerontol 1998;53A:M235-41.

18 Eaton CB, Reynes J, Assaf AR, et al. Predicting physical activity change in men and women in two New England communities. Am f Prev Med 1993;9:209-19.

19 Chinn DJ, White M, Harland J, et al. Barriers to physical activity and socioeconomic position: implications for health promotion. $\mathcal{F}$ Epidemiol Community Health 1999;53:191-2. 
20 Owen N, Bauman A. The descriptive epidemiology of a sedentary lifestyle in adult Australians. Int 7 Epidemiol entary lifestyle

21 Bandura A. Social learning theory. New Jersey: Prentice Hall, 1977.

22 Rosenstock IM. Historical origins of the health belief model. Health Educ Monographs 1974;2:328-35.

23 Skinner BF. Science and human behavior. New York: Macmillan, 1963.

24 Mackenbach JP, van de Mheen $\mathrm{H}$, Stronks K. A prospective cohort study investigating the explanation of socioeconomic inequalities in health in the Netherlands. Soc $\mathrm{Sci}$ Med 1994;38:299-308.

25 van der Meer J. Equal care, equal cure? [ $\mathrm{PhD}$ dissertation.] Amsterdam: Thesis Publishers, 1998.

26 van den Brandt P, Bausch-Goldbohm S. A prospective cohort study on diet and cancer in the Netherlands. Design, conduct, analysis, and first results after 3,3 years of follow-up. [PhD dissertation.] Maastricht: Universitaire Pers Maastricht, 1993.

27 Liberatos P, Link BG, Kelsey JL. The measurement of social class in epidemiology. Epidemiol Rev 1988;10:87-121.

28 Class in epidemiology. Epidemiol Rev 1988;10:87-121. Survey. [In Dutch]. Voorburg, Heerlen: CBS, 1989.

29 Hunt SM, McEwen J, McKenna SP. Measuring health status. London: Croom Helm, 1986.

30 Garretsen HFL. Problem drinking. Determination of prevalence, influencing factors and possibilities for prevention. [In Dutch]. [PhD dissertation.] Lisse: Swets and Zeitlinger BV, 1983.

31 Ormel J. Difficulties with living or a difficult life. [In Dutch]. [PhD dissertation.] Groningen: Rijksuniversiteit Groningen, 1980
32 Sanderman R, Arrindel WA, Ranchor AV, et al. The measurement of personality characteristics using the Eysenck Personality Questionnaire (EPQ); a manual. [In Dutch]. Groningen: Noordelijk Centrum voor Gezondheidsvraagstukken, 1995.

33 Central Bureau of Statistics (CBS). Questionnaire Life Situation Research. [In Dutch]. Voorburg, Heerlen: CBS, 1986.

34 Hendriks AAJ, Ormel J, van de Willige G. Long lasting difficulties measured with a self assessment questionnaire and semistructured interview: a theoretical and empirical comparison. [In Dutch]. Gedrag en Gezondheid 1990;18:27383

35 Fishbein M, Ajzen I. Belief, attitude, intention and behavior: an introduction to theory and research. Reading, MA: AddisonWesley, 1975

36 Prochaska JO, Velicer WF. The transtheoretical model of behavioural change. Am $\mathcal{F}$ Health Promotion 1997;12:38-48.

37 Ajzen I. The theory of planned behavior. Organizational Behavior Human Decision Processes 1991;50:179-211.

38 Skinner EA. A guide to constructs of control. F Personal Soc Psychol 1996;71:549-70.

39 Thompson SC, Spacapan S. Perceptions of control in vulnerable populations. F Soc Issues 1991;47:1-21.

40 Guagnano G, Acredolo C, Hawkes GR, et al. Locus of control: demographic factors and their interactions. F Soc Behaviour Personal 1986;1:365-80.

41 Landau R. Locus of control and socioeconomic status: does internal locus of control reflect real resources and opportunities or personal coping abilities? Soc Sci Med 1995;41: 1499-505.

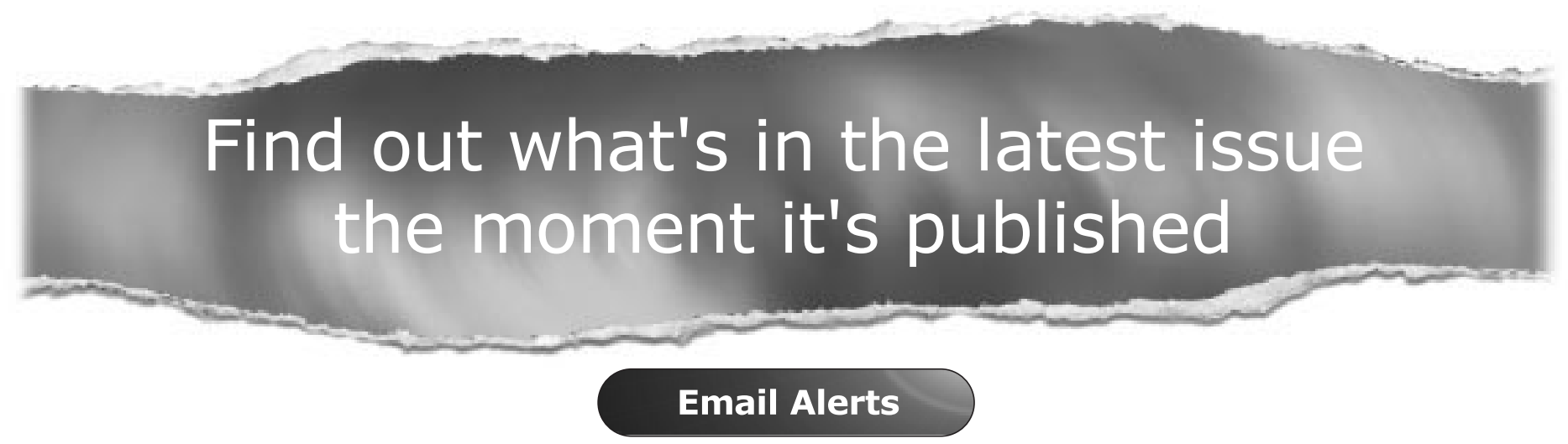

Sign up to receive the table of contents by email every month. You can select from three alerts:

Table of Contents (full), TOC Awareness (notice only); Journal of Epidemiology and Community Health related announcements.

www.jech.com 